\title{
LIBERAÇÃO DO ÁCIDO TRANEXÂMICO ENCAPSULADO VIA GELIFICAÇÃO IÔNICA
}

\author{
G. MAESTRI ${ }^{1}$, R. L. BOEMO ${ }^{2}$, L. A. SOARES ${ }^{1}$ e A. P. S. IMMICH ${ }^{1}$ \\ ${ }^{1}$ Universidade Federal de Santa Catarina, Campus Blumenau - SC \\ ${ }^{2}$ Centro Otorrinolaringológico de Florianópolis, Departamento de Otorrinolaringologia e \\ Fonoaudiologia de Florianópolis - SC \\ E-mail para contato: gabriela.maestri@grad.ufsc.br
}

\begin{abstract}
RESUMO - Fármacos antifibrinolíticos são utilizados em ocorrências de sangramento intenso, a fim de produzir um coágulo e interromper o sangramento. No entanto, o fármaco em sua forma oral e/ou injetável não atua diretamente no sangramento, podendo muitas vezes, não apresentar o efeito desejado. Uma alternativa de administração de fármacos no local de interesse, ou seja, região do sangramento, se dá através dos dispositivos de liberação controlada, que podem se apresentar na forma de adesivos, hidrogéis e matrizes poliméricas com fármaco encapsulado. Este trabalho tem como objetivo produzir cápsulas do fármaco antifibrinolítico ácido tranexâmico, em sua forma purificada, pelo método de gelificação iônica. Os testes de liberação do fármaco purificado e encapsulado foram realizados em meio aquoso à $37^{\circ} \mathrm{C}$ e comparados com a liberação do fármaco purificado e não purificado. As amostras contendo fármaco purificado tiveram uma liberação de $85 \%$ após 270 minutos, enquanto aquelas que continham fármaco não purificado apresentaram um percentual de liberação de $47 \%$ no mesmo tempo. Este estudo mostra a interferência que os excipientes adicionados ao fármaco exercem no processo de liberação, dificultando o desprendimento do fármaco, bem como a sua atividade no processo a que se destinam.
\end{abstract}

\section{INTRODUÇÃO}

De acordo com estudos de Assunção et. al. (2014), a encapsulação vem sendo utilizada a fim de oferecer um produto diferenciado e que tenha utilidade à saúde humana, como a encapsulação de agentes antimicrobianos, antioxidantes ou antiinflamatórios. Esta técnica tem como principal objetivo proteger, isolar e controlar a liberação de substâncias. Alguns dos objetivos deste método incluem: reduzir interações do núcleo com fatores ambientais, retardar alterações de perda de material do núcleo, aumentar a vida útil do produto e ter a possibilidade de uma liberação controlada da substância encapsulada, tais como aromas, óleos, alimentos, cremes e fármacos.

A liberação controlada de fármacos tem como intuito o controle temporal da concentração de fármaco em uma taxa de tempo, in vivo, para que ofereça o benefício desejado. Este sistema envolve a associação, química ou física, dos fármacos que quando administrados no paciente, tenham o intuito de controlar, de forma pré-determinada, a taxa de 
liberação do medicamento a partir deste sistema, e/ou então conduzir o fármaco até o meio específico em que este deve atuar, como mostra o trabalho de Ribeiro (2014).

Estudos de Rodrigues et. al. (2013) afirmam que a encapsulação de fármacos para administração controlada, pode acontecer por várias técnicas, tal como pulverização, coacervação complexa, leito fluidizado e gelificação iônica. Esta última, por sua vez, se destaca por ser simples e de baixo custo. Ocorre quando uma solução polimérica contendo o material do núcleo é gotejada sobre uma solução iônica, formando as cápsulas imediatamente, como mostra Pasqualim et. al (2010).

Luz et. al. (2012) indica que uma das ocorrências de maior responsabilidade por mortes hospitalares precoces e tardias é o sangramento excessivo. Além disso, pacientes com trauma de sangramentos podem vir a desenvolver um distúrbio de coagulação característico e complexo, onde fatores etiológicos múltiplos, como diluição e consumo, são responsáveis pelo seu desenvolvimento. Estes sangramentos são efetivamente tratados com fármacos antifibrinolíticos, tal como ácido aminocapróico e ácido trans-aminoexâmico (ácido tranexâmico).

O ácido tranexâmico, quando na forma de comprimido, possui em sua composição alguns excipientes, muitas vezes indesejáveis no processo de liberação controlada deste medicamento, pois, estes excipientes podem vir a atrapalhar ou até interromper a liberação do fármaco. Este medicamento tem como excipientes amido de milho, estearato de magnésio, poli(álcool vinílico) e fosfato de cálcio.

O objetivo deste trabalho é avaliar e comparar a cinética de liberação do fármaco antifibrinolítico ácido tranexâmico em sua forma comercial (comprimido) com o composto purificado, encapsulado via gelificação iônica com alginato de sódio, para auxiliar em tratamentos de sangramentos excessivos, promovendo maior comodidade, conforto e segurança ao paciente.

\section{METODOLOGIA}

Os experimentos foram realizados no Laboratório de Beneficiamento da Universidade Federal de Santa Catarina, Campus Blumenau.

\subsection{Materiais}

O fármaco antifibrinolítico utilizado foi o ácido tranexâmico, de nome comercial Transamin, em sua forma sólida (comprimido de $250 \mathrm{mg}$ ), adquirido no mercado nacional. Os materiais utilizados na encapsulação do fármaco foram alginato de sódio e cloreto de cálcio, marca VETEC. O solvente usado na purificação do fármaco ácido tranexâmico foi álcool etílico absoluto, grau de pureza $99 \%$, da marca Chemicals. Os materiais foram usados sem tratamentos prévios.

\subsection{Métodos}

2.3.1. Purificação do ácido tranexâmico: Um comprimido de Transamin foi macerado e solubilizado em água destilada à temperatura ambiente e agitação magnética por $1 \mathrm{~h}$. A 
solução foi filtrada em papel filtro e em seguida, mantida em repouso para evaporação da água por aproximadamente $15 \mathrm{~h}$. Após, etanol foi adicionado para dissolver o álcool polivinílico e cristalizar o fármaco, que foi acondicionado em dessecador por aproximadamente $10 \mathrm{~h}$ para completa remoção de umidade. O processo é ilustrado na Figura 1.

Figura 1 - Processo de purificação do ácido tranexâmico

1 comprimido de TRANSAMIN em 0,3 $\mathrm{mL}$ de água destilada

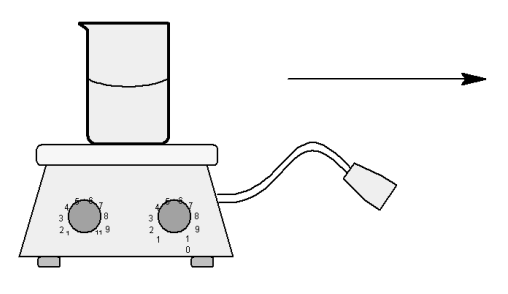

Filtração para retirada de excipientes insolúveis

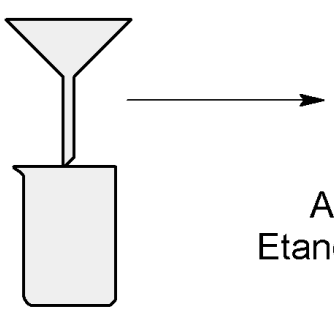

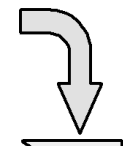

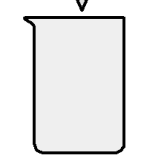

Adição de $2 \mathrm{~mL}$ de Etanol para solubilização do PVA

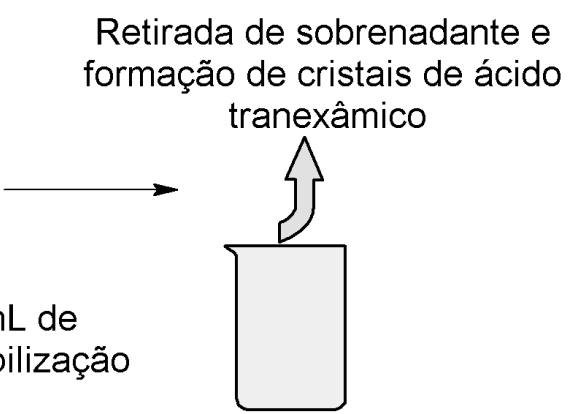

2.3.2. Obtenção das cápsulas via gelificação iônica: Uma solução de alginato de sódio em água destilada, com concentração de $20 \%$ foi preparada à $40{ }^{\circ} \mathrm{C}$ e agitação magnética constante até a completa solubilização do material. Separadamente, uma solução salina de 0,1 $\mathrm{M}$ de $\mathrm{CaCl}_{2}$ foi preparada à temperatura ambiente com agitação. A solução de alginato foi gotejada com seringa convencional galga 22 na solução salina para formação das cápsulas. Em seguida, as cápsulas foram filtradas e lavadas com água destilada, para remoção de sal, e acondicionadas em ambiente seco e refrigerado. Todos os testes foram realizados em triplicata.

2.3.3. Obtenção das cápsulas via gelificação iônica contendo fármaco: As cápsulas foram produzidas como descritas no item anterior (2.3.2), com a adição de 1 comprimido macerado de TRANSAMIN não purificado na solução de alginato de sódio. O procedimento de formação e acondicionamento das cápsulas é o mesmo do item anterior.

2.3.4. Obtenção das cápsulas via gelificação iônica contendo fármaco purificado: As cápsulas foram produzidas como descritas no item 2.3.2, com adição de ácido tranexâmico purificado (produto da purificação de 1 comprimido) à solução de alginato de sódio. $\mathrm{O}$ procedimento para formação das cápsulas e seu acondicionamento é o mesmo do item 2.3.2.

2.3.5. Liberação do fármaco: Os testes de liberação foram feitos em água destilada à 37 ${ }^{\circ} \mathrm{C}$ com leve agitação magnética para homogeneização do meio. A liberação do fármaco foi medida em um espectrofotômetro UV-vis M51 da marca BEL Photometics, no comprimento de onda de $300 \mathrm{~nm}$.

2.3.6. Morfologia das cápsulas: A morfologia foi observada em um estereomicroscópio binocular com base diascópica, marca Nova Optical. O peso médio das cápsulas foi medido de acordo com a metodologia estabelecida pela Farmacopéia Brasileira (1996).

\section{RESULTADOS E DISCUSSÃO}


As cápsulas foram analisadas quanto à sua morfologia, ilustrado na Figura 1. As cápsulas apresentaram forma circular, peso médio de $17 \mathrm{mg}$ e baixa porosidade.

Figura 1 - Cápsulas contendo ácido tranexâmico purificado com ampliação de 5x. a) antes da liberação; b) depois da liberação.

a)

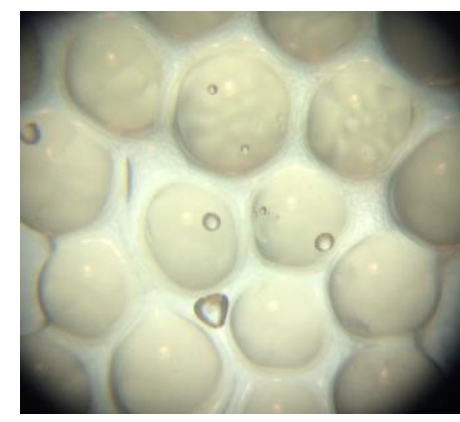

b)

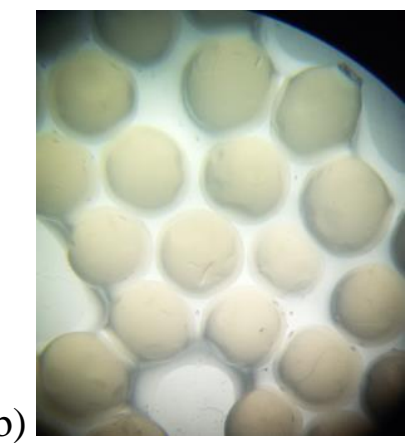

Algumas cápsulas apresentaram pequenos vincos em sua superfície após a liberação, que podem ter sido ocasionados pela erosão da cápsula polimérica durante o teste de liberação. Este fator não prejudicou a liberação e nem sua futura aplicação, uma vez que não rompeu a cápsula por completo.

Os testes de liberação em meio aquoso apresentaram uma taxa máxima de liberação de $85 \%$ nas cápsulas contendo fármaco purificado e de $47 \%$ nas amostras com fármaco não purificado, após 270 minutos. A figura 3 apresenta o gráfico da cinética de liberação.

Figura 3 - Cinética de liberação de fármaco ácido tranexâmico

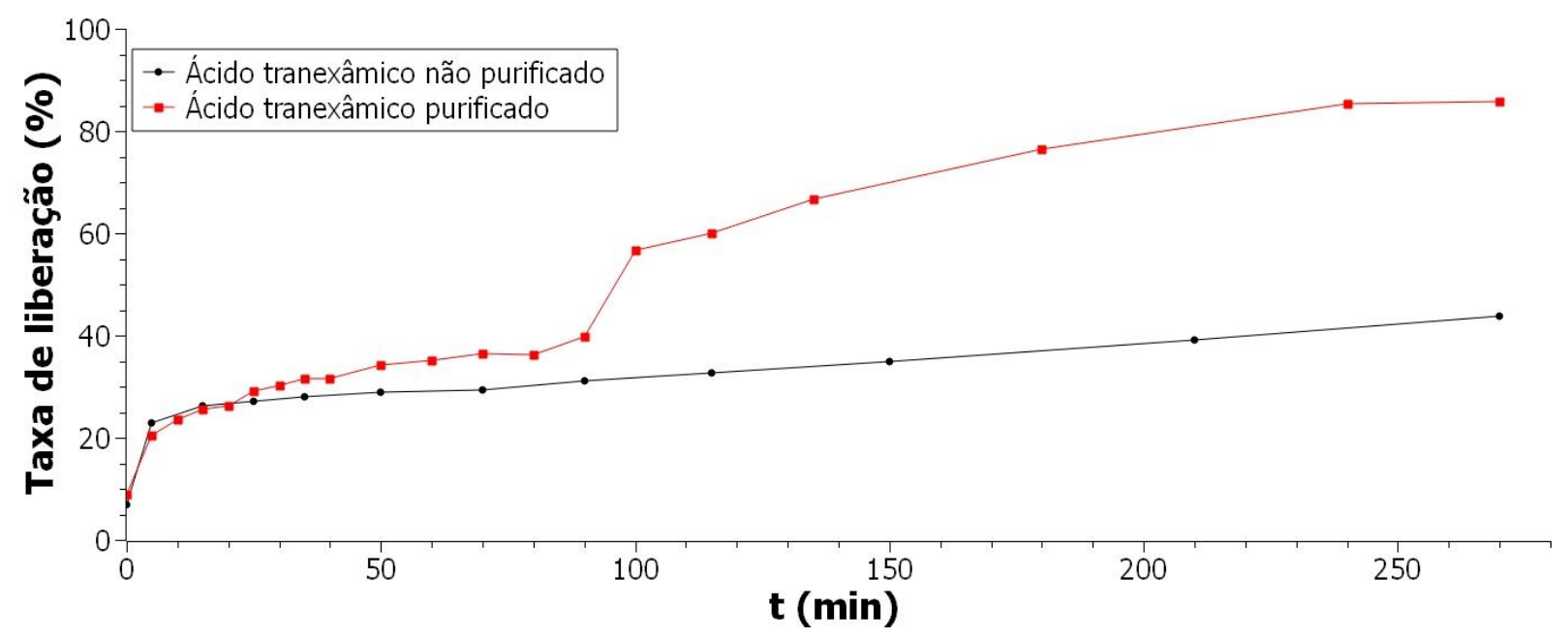

O gráfico da Figura 3 mostra que a amostra que continha fármaco purificado apresentou uma liberação mais rápida e eficiente do que a amostra com fármaco não purificado, principalmente após 90 minutos. Isto pode ser acontecido devido à quantidade de excipientes presentes na amostra não purificada, o que pode ter influenciado na liberação do fármaco, impedindo sua saída quando em contato com o meio de liberação. A presença do amido de milho, um dos excipientes, pode ter prejudicado a saída do ácido tranexâmico, uma vez que é um espessante e intumesce em meio líquido aquecido, dificultando a saída do fármaco. Além 
disso, o poli (álcool vinílico), outro excipiente, pode também ter dificultado a liberação do fármaco. Por ser um polímero sintético utilizado na produção de adesivos, colas e filmes, o PVA pode ter atuado a favor da agregação do material e não na dispersão para liberação do fármaco. Com isto, acredita-se que este excipiente possa ter criado uma película na parte interna da cápsula, dificultando assim, a saída do material desejado.

\section{CONCLUSÃO}

O estudo mostrou a viabilidade do processo de encapsulação do ácido tranexâmico via gelificação iônica do alginato de sódio em solução salina. Os testes de liberação mostraram que as amostras contendo fármaco purificado tiveram um percentual de liberação de $38 \%$ a mais do que as amostras que continham fármaco não purificado, após 270 minutos. Com isso, entende-se que os excipientes contidos no ácido tranexâmico prejudicaram a sua liberação em meio aquoso, e, portanto, a produção de cápsulas com fármaco não purificado não apresentam uma liberação eficiente para as devidas aplicações.

\section{AGRADECIMENTOS}

Agradecemos ao Laboratório de Beneficiamento e ao Laboratório de Fenômenos de Transporte da Universidade Federal de Santa Catarina.

\section{REFERÊNCIAS}

ASSUNÇÃO, L. S.; FERREIRA, C. D.; CONCEIÇÃO, E. J. L.; NUNES, I. L. Estudo prospectivo sobre encapsulamento de compostos bioativos. Revista GEINTEC, v. 4, n. 4, p. 1382-1391, 2014.

FARMACOPÉIA BRASILEIRA. 4 ed. São Paulo: Atheneu, 1996. Parte II.

LUZ, L.; SANKARANKUTTY, A.; PASSOS, E.; RIZOLI, S.; FRAGA, G. P.; NASCIMENTO, B. Ácido tranexâmico no tratamento da hemorragia no trauma. Rev. Col. Bras. Cir. 2012.

PASQUALIM, P.; CULPI, T. A.; KAMINSKI, G. A. T.; FIN, M. T.; SASSO, D. G. B.; COSTA, C. K.; MIGUEL, M. D.; FUJIWARA, G. M.; RODRIGUES, B. H.; ZANIN, S. M. W. Microcápsulas de alginato de cálcio e óleo vegetal pela técnica de gelificação iônica: um estudo da capacidade de encapsulamento e aplicação dermatológica. Visão acadêmica, v. 11, n. 1, Curitiba, 2010.

RIBEIRO, S. M. A. Encapsulação e libertação controlada de fármacos. Dissertação de mestrado. Escola Superior de Tecnologia e Gestão, Instituto Politécnico de Bragança, 2014.

RODRIGUES, V. C.; TOSONI, S. F. Características físico-químicas e antioxidantes de própolis microencapsulada com diferentes tipos de materiais encapsulantes. Trabalho de conclusão de curso, Campo Mourão, 2013. 